\title{
ARTIGOS
}

\section{PRÁTICAS SUSTENTÁVEIS E NÃO SUSTENTÁVEIS NA PRODUÇÃO DE SANDÁLIAS DE COURO CAPRINO EM CABACEIRAS-PB}

SUSTAINABLE AND UNSUSTAINABLE PRACTICES IN THE PRODUCTION OF CAPRINE LEATHER SANDALS IN CABACEIRAS-PB

\author{
ANA AMÉLIA ALBUQUERQUE DE OLIVEIRA CASTANHA | UFCG \\ GEISLAYNE MENDONÇA SILVA | UFCG \\ JULIA TELES DA SILVA, Dra. | UFCG \\ ITAMAR FERREIRA DA SILVA, Dr. | UFCG
}

\begin{abstract}
RESUMO
Este artigo tem o objetivo de apresentar as práticas sustentáveis e não sustentáveis da produção de sandálias rasteiras de couro caprino na Cooperativa Arteza em Cabaceiras/PB a partir da análise sistêmica do produto. Para compreender as etapas de fabricação foram realizadas visitas técnicas no ambiente produtivo e entrevistas sem roteiro com os produtores. Com a análise das etapas produtivas, foram identificadas práticas sustentáveis, e outras que necessitam de estudos e intervenção, resultando em um diagnóstico que propõem melhorias produtivas.
\end{abstract}

PALAVRAS-CHAVE: Sandálias; Sustentabilidade; Couro; Design Sistêmico; Cabaceiras-PB.

\begin{abstract}
This article aims to present the sustainable and unsustainable aspects of the goat skin flat sandals production at Cooperativa Arteza in Cabaceiras/PB, identified by a systemic analysis of the product. To understand the manufacturing stages, technical visits in the production site were made, as well as interviews without script with producers. From the analysis of the production stages, sustainable practices were identified, as well as practices that need studies and intervention - resulting in a diagnosis that proposes productive improvements.
\end{abstract}

KEY WORDS: Sandals; Sustainability; Leather; Systemic Design; Cabaceiras-PB. 


\section{INTRODUÇÃO}

A busca por práticas sustentáveis dentro do processo produtivo das empresas vem ganhando força em decorrência da mudança de comportamento dos consumidores, que aos poucos estão se tornando mais exigentes com as questões ambientais.

A sociedade que sustentava formas de produção danosas começa a demonstrar interesse por soluções mais ecológicas, iniciando um processo de aprendizagem, onde se busca efetivar as escolhas por meio do apoio e reconhecimento a produtos/serviços que busquem redução no nível de produção e consumo material (MANZINI, 2008, p.26).

Com o progresso da revolução verde as empresas líderes começaram a voltar à atenção para estratégias proativas, percebendo que poderiam, com isso, melhorar sua competitividade diante do mercado e criar valor social, superando deste modo empresas ultrapassadas cuja tecnologia empregada consistia em modelos prejudiciais (HART, 2006 apud CLEMENTINO, 2017).

Segundo Schenini et al. $(2014$, p.16) o desenvolvimento de produtos e processos ambientalmente sustentáveis melhoram a imagem corporativa e da marca, economizando capital e abrindo novos mercados para produtos que tenham o intuito de satisfazer as necessidades de alta qualidade de vida.

Todavia, de acordo com Kazazian (2009, p. 55) fundamentalmente não existem produtos ecológicos, pois de algum modo eles afetarão o meio ambiente, o que existe é uma busca continuada por melhorias.

Se contrapondo a essa situação, o design vem progressivamente deixando de ser apenas a criação de um bom produto, ampliando cada vez mais o seu escopo, passando a levar em consideração os processos, relações e fluxos de matéria e energia.

Esse artigo tem como objetivo trazer um olhar sistêmico para um produto artesanal, colocando em evidência os diferentes processos de fabricação envolvidos, visando identificar as práticas sustentáveis e não sustentáveis durante todo o ciclo produtivo,

Nessa pesquisa, o objeto de estudo foi a sandálias rasteiras em couro caprino (Figura 01) na Cooperativa Arteza em Cabaceiras-PB, sendo escolhida em decorrência de seu destaque produtivo e de vendas.

Através de visitas técnicas ao local de produção, foram obtidas informações sobre as etapas de confecção da sandália a partir de entrevistas com o produtores e realizado o registro fotográfico dos setores produtivos.

Identificar as etapas produtivas e compreender suas técnicas e procedimentos possibilita diagnosticar o quão sustentáveis são estas práticas, permitindo avaliar os problemas e apresentar as possíveis soluções ambientais de uma maneira bastante pontual.

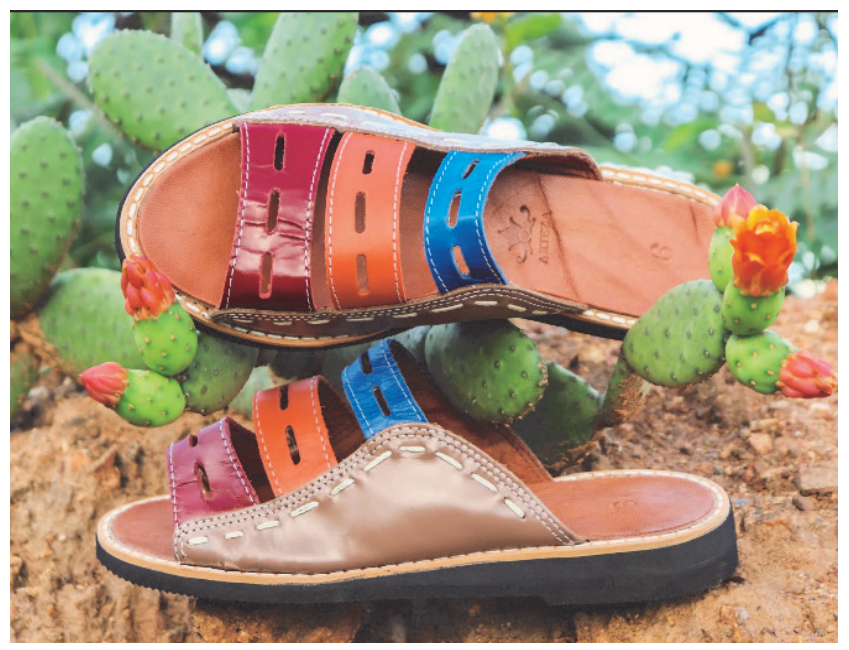

Figura 01 - Sandália em couro caprino Fonte: Arteza Cooperativa (2019)

\section{PRÁTICAS SUSTENTÁVEIS E ANÁLISE SIS- TÊMICA DO PRODUTO}

No campo do Design, a sustentabilidade tem ganhado importância nos últimos anos, tanto que o designer começa a se questionar, durante a concepção de produtos, sobre aspectos relacionados ao uso de recursos naturais, a emissão de poluentes e a geração de resíduos.

Santos $(2012$, p.27) afirma que as preocupações com o meio ambiente vêm mudando a maneira como os designers concebem os produtos, aprofundando métodos e estratégias focadas na sustentabilidade, objetivando suprir cenários complexos.

Com isso, surgiram diferentes metodologias para lidar com a questão ambiental, a partir do redesenho de produtos e processos, com o ecodesign, a análise de ciclo de vida e o design sistêmico.

É importante levar em conta que sustentabilidade não está relacionada apenas aos aspectos materiais, mas também aspectos culturais, sociais e econômicos.

O conceito de desenvolvimento sustentável é baseado em três aspectos: econômico, social e ambiental. Estes constituem o Triple Bottom Line, ou seja, os três pilares da sustentabilidade (PAZ, LAUS e FARIAS, 2017; MENEZES et al., 2016).

Dentro de cada um desses três aspectos encontram-se diversos setores onde as atividades desenvolvidas impactam o meio ambiente, umas de forma mais agressiva e outras causando menos danos, tanto na extração quanto no descarte de materiais. (PAZ; LAUS; FARIAS, 2017). 
Alves e Nascimento (2016) apresentam três principais razões que embasam a necessidade de introduzir práticas sustentáveis nas atividades desenvolvidas por empresas:

- O aumento da conscientização ambiental da sociedade e o temor da organização em relação a problemas com sua imagem e com sua reputação;

- O efeito de otimização operacional decorrente de práticas de eficiência ambiental; e

- As questões éticas com que os proprietários, gestores e acionistas das organizações se deparam.

A CATALISA (2019) define práticas sustentáveis como o conjunto de ações que tem por objetivo levar o ser humano, nos seus diferentes papéis, a reassumir a condição de componente do ecossistema natural, catalisar a difusão e aplicação do conhecimento.

Corroborando com esta afirmação, Alves e Nascimento (2016) asseguram que práticas sustentáveis são ações praticadas de forma voluntária por empresas que objetivam melhorar o desempenho ambiental e o desempenho social, além de cumprir às exigências legais. Apesar de que Santos et al. (2016) ressaltam que no Brasil, houve demora das empresas nacionais em internalizar o conceito de desenvolvimento sustentável.

Dessa maneira, Spillere et al. (2016) afirmam que as indústrias que mais precisam inserir práticas sustentáveis em seus processos são aquelas que utilizam energia elétrica demasiadamente, ou as indústrias exploradoras de recursos naturais e seus derivados.

Na área do design sustentável, a proposta é de se ter um olhar sistêmico sobre o ciclo de vida do produto. Ou seja, é preciso prestar atenção aos processos e materiais envolvidos desde a extração da matéria-prima até o descarte do produto. Isso inclui os resíduos gerados e a energia consumida para produzi-lo.

Tradicionalmente, o design é focado no produto e trabalha com um pensamento linear da cadeia produtiva - em que entram matéria-prima e energia de um lado e saem produtos e resíduos do outro. Isso muda quando o aspecto ecológico é levado em conta.

Conforme Lamb e Nass (2014), na filosofia do pensamento do ciclo de vida, o produto é analisado de maneira holística, considerando-se todas as suas fases de produção e seus deslocamentos (Figura 02).

Luigi Bistagnino, com o Design Sistêmico, propõe que os designers tenham um olhar ainda mais amplo do que o ciclo de vida do produto, passando a levar em conta todo o processo produtivo. $\mathrm{O}$ autor propõe:
"Ver o mundo produtivo de maneira sistêmica, distanciado do foco exclusivo do produto ou do seu ciclo de vida, estendendo a atenção à cadeia produtiva inteira, considerando a problemática inerente dos descartes de trabalho e a própria escassez de matéria-prima. Os designers terão essa nova responsabilidade. Hoje as condições de contexto requerem, e sempre mais requererão, que os produtos venham concebidos sob a ótica do sistema." (BISTAGNINO, 2009, p. 17)

O autor propõe que se faça uma análise de todo o processo produtivo, observando todos os inputs e outputs envolvidos e buscando criar um sistema em que, idealmente, os outputs de um processo sejam inputs de outro, como acontece na natureza.

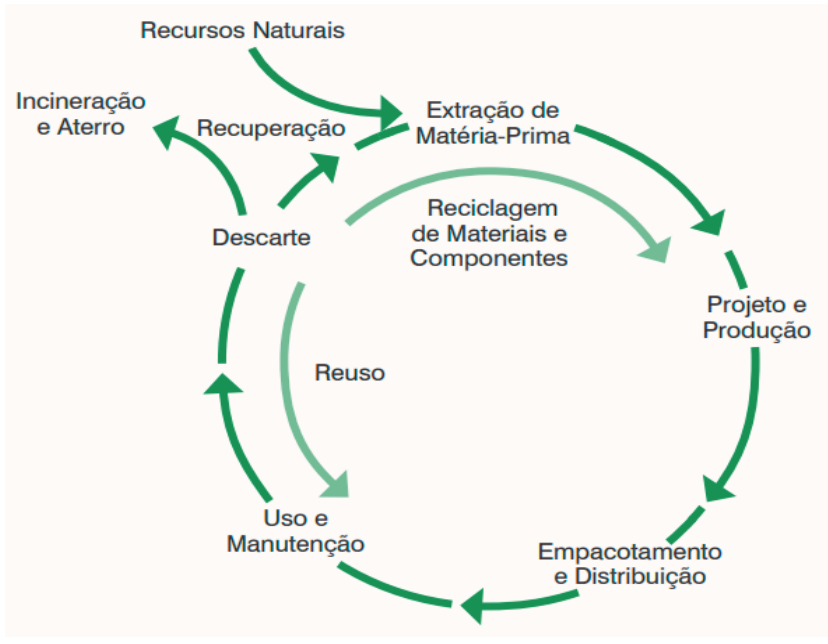

Figura 02 - Ciclo de Vida do Produto

Fonte: Lamb e Nass (2014)

$\mathrm{Na}$ natureza não existem descartes ou desperdícios, pois todos os elementos são reabsorvidos pelo sistema. Bistagnino propõe que o design deve buscar criar sistemas amplos, que geram ciclos fechados de matéria e energia - sistemas que levem em conta não apenas o produto, mas toda a sociedade, envolvendo valores econômicos e culturais.

O design sistêmico tem a proposta de agir localmente, olhando para um território, buscando soluções locais, que fortaleçam a identidade e a produção do território. Propõe também criar sistemas locais que se sustentem e se reproduzam autonomamente (PÊGO, 2014).

\section{O CORTUME E O ARTESANATO, A ARTEZA E OS ARTIGOS DE COURO}

Atualmente, segundo o Centro de Indústrias de curtumes do Brasil (CICB) o Brasil tem o maior rebanho comercial do mundo, sendo 310 plantas curtidoras, 2.800 indústrias de 
componentes para couro e calçados e 120 fábricas de máquinas e equipamentos, 40.000 empregos diretos e movimentação de US\$ 3 bilhões a cada ano. (BRASIL, 2019).

O Nordeste foi pioneiro na criação de bovinos no país, tendo havido investimentos de valorização na forma de plantar e fortificar a terra para o desenvolvimento da agropecuária. Tornou-se uma economia rentável, em virtude do fornecimento do leite, da carne e do couro, material necessário para a confecção de diversos artefatos úteis para a vida dos camponeses, sendo expandida para os caprinos e ovinos em virtude da maior resistência às adversidades climáticas. (CASTANHA, 2017).

Na região Nordeste, o bode e o carneiro se adaptaram mais ao clima quente do que o gado e explica a diferença entre a pele ovina e caprina, ressaltando distinções como o fato de a pele ovina possuir leveza, delicadeza e elegância. As fibras que a formam tornam certos tipos de produtos diferenciados, não somente as fibras como o tamanho e a espessura da peça (COBRASIL, 2019).

No século XIX a Paraíba se destacava com um grande número de fábricas de couro conhecidas como curtume (CASTANHA, 2017). Todavia, atualmente existem apenas quatro curtumes ativos na Paraíba (em Monteiro, Itabaiana, Cabaceiras e Campina Grande), que mantém um bom nível de produção de peças em couro que são comercializadas entre os próprios municípios, entre estados e até internacionalmente. Em Cabaceiras foi fundada em 31/07/1998 a cooperativa Arteza, a partir da iniciativa do curtumeiro José Carlos de Castro em parceria com alguns artesãos, prefeitura municipal, governo do estado, através da Secretaria de Indústria e Comércio, SEBRAE, SENAI, Universidades, por perceber a decadência dos curtumes e artesanatos em couros (artezacooperativa.com.br).

Iniciou com 28 sócios, e atualmente conta com 82 associados. Tinha uma produção de 500 peles de bode, 5 toneladas de couro de boi e vendia pouco mais de 100 peças de artesanato por mês. Hoje conta com uma produção de 12 mil peles de bode, 30 toneladas de couro de boi e venda de centena de milhares de peças por mês. Trazendo uma movimentação mensal de mais de $1 \mathrm{mi}-$ Ihão e duzentos mil reais. (MONTE, 2018).

$O$ regimento interno da cooperativa define que cada família fique responsável pela produção de um produto, evitando a competitividade entre os próprios associados e garantindo um mercado mais justo e dinâmico. Essa determinação trouxe vantagens em virtude da variedade de produtos produzidos, que vão desde a produção do famoso chapéu de vaqueiro, bolsas, carteiras, chaveiros e até objetos de decoração (artezacooperativa.com.br).
A ARTEZA é conhecida em todo o Brasil e em 40 países por lançar-se no mercado com uma proposta de curtimento vegetal, com baixíssimo tratamento químico, qualidade diferenciada aliada à inovação tecnológica trazida pela SICTCT (Secretaria da Indústria, Comércio, Turismo, Ciência e Tecnologia) através do programa COMPET/CNPq, em parceria com o SENAI/CTCC e apoiado pela Prefeitura Municipal de Cabaceiras e o SEBRAE. Também é conhecida pelo uso de couro caprino, que possui uma pele melhor para se trabalhar com o artesanato (artezacooperativa.com.br).

\section{PROCEDIMENTOS METODOLÓGICOS}

A metodologia seguiu as seguintes etapas:

a) Pesquisas bibliográficas para aprofundamento das problemáticas envolvendo o couro no processo de confecção de produtos;

b) Definição do objeto de estudo da presente pesquisa (sandálias rasteiras em couro caprino);

c) Visita técnica "in loco", para observação com registro fotográfico das etapas produtivas;

d) Entrevista sem roteiro com os artesãos da cooperativa para levantamento de informações quanto ao processo de fabricação de sandálias e os prováveis impactos ao meio ambiente.

e) Análise de cada etapa do processo produtivo, para definição das práticas sustentáveis e não sustentáveis. Com a pesquisa bibliográfica foi possível fazer, de modo geral, um breve diagnóstico dos efeitos sobre o meio ambiente do processo de curtimento e trabalhabilidade dos produtos derivados do couro.

Com as visitas in loco e realização de entrevista com o responsável por gerenciar a cooperativa, o senhor Lucas Castro, identificou-se a sandália rasteira como item de maior produção e destaque de vendas. Onde há o engajamento do maior número de cooperados envolvidos. Logo, o produto que possivelmente, gera maior trabalhabilidade e resíduos para o meio ambiente. Também foram acompanhadas as etapas de produção da sandália, realizado registro fotográfico das operações e obtidos relatos dos artesãos sobre as ferramentas e procedimentos.

\section{ANÁLISE SISTÊMICA DAS SANDÁLIAS DE COURO CAPRINO}

A partir da observação do processo produtivo, foram identificadas as seguintes etapas do sistema de confecção de sandálias:
1) Pecuária
2) Abate do bode e obtenção do couro
3) Curtimento do couro 
4) Pintura do couro

5) Corte das peças

6) Montagem/Fôrma

7) Acabamento/lixadeira

8) Venda varejo e fornecedores

As etapas de confecção das sandálias foram analisadas a partir de uma abordagem sistêmica, sendo identificados os elementos envolvidos na produção, quais fases são gerados descartes e como isso poderia ser evitado. Para essa análise, foram relacionadas cada etapa no processo das sandálias de couro com as etapas do ciclo de vida de um produto, que consistem em:

1 - Extração da Matéria-Prima;

2 - Fabricação;

3 - Distribuição para o mercado revendedor;

4 - Uso;

5 - Descarte

\subsection{Etapa 01 - Extração da matéria-prima}

Consiste na pecuária extensiva, cujos animais, mais especificamente os caprinos são criados soltos em áreas extensas, sem finalidade de produtividade.

Os caprinos são selecionados e abatidos para obtenção da pele. Esse material passa pelo processo de curtimento vegetal, onde é utilizada a casca da espécie arbórea Angico (Figura 03).

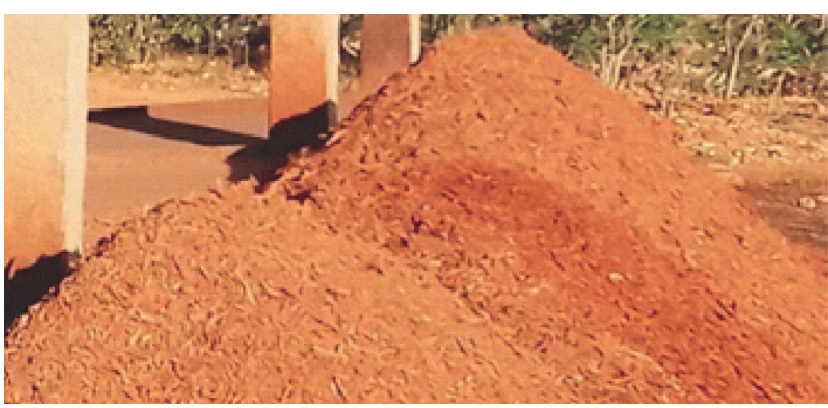

Figura 03 - Casca do angico Fonte: Autores (2019)

Essas cascas são compradas nas cidades de Sumé, Congo, Camalaú, Custódia, Serra Talhada e Betânia. Embora o tanino vegetal se apresente como prática sustentável por não agredir o meio ambiente, algumas outras etapas no processo de curtimento são consideradas não sustentáveis, uma vez que há o uso desenfreado de água em uma região semiárida, não existindo tratamento de efluentes e de resíduos sólidos que são lançados diretamente nos rios.

Atualmente tem um projeto voltado para o tratamento desses resíduos e rejeitos líquidos, porém ainda não executado. Após o curtimento, o couro é enviado para a cooperativa como matéria-prima.

A partir da análise da etapa de extração da matéria-prima, chegou-se ao Quadro 1.

\begin{tabular}{|l|l|l|l|}
\hline ATIVIDADE & PRÁTICAS NÃO SUSTENTÁVEIS & PRÁTICAS SUSTENTÁVEIS & SUGESTÕES \\
\hline $\begin{array}{l}\text { Pecuária, abate do bode } \\
\text { e obtenção do couro }\end{array}$ & Forma do abate & $\begin{array}{l}\text { Os animais são criados } \\
\text { fora de confinamento } \\
\text { Os animais são adaptados } \\
\text { ao meio ambiente local }\end{array}$ & $\begin{array}{l}\text { Modo de abate menos } \\
\text { agressivo ao animal }\end{array}$ \\
\hline $\begin{array}{l}\text { Curtimento do couro e } \\
\text { obtenção da casca do angico }\end{array}$ & $\begin{array}{l}\text { Não é realizado um planejamento à } \\
\text { longo prazo da quantidade de árvores } \\
\text { disponíveis para extração da casca. }\end{array}$ & $\begin{array}{l}\text { Curtimento vegetal a } \\
\text { partir do tanino. }\end{array}$ & $\begin{array}{l}\text { Manejo sustentável da extração da } \\
\text { casca do Angico a partir de um estu- } \\
\text { do da área envolvendo silvicultura. }\end{array}$ \\
\hline Uso de água & $\begin{array}{l}\text { Resíduos e rejeitos sólidos dispen- } \\
\text { sados diretamente nos rios. }\end{array}$ & --- & $\begin{array}{l}\text { Tratamento de resídu- } \\
\text { os e rejeitos sólidos. }\end{array}$ \\
\hline
\end{tabular}

Quadro 1 - Etapa 01 - Extração da Matéria-prima

Fonte: Autores (2019)

\subsection{Etapa 02 - Fabricação}

Chegando à cooperativa, o couro passa por um processo de acabamento onde é pintado com tinta que possui componentes à base de petróleo (Figura 04)

Uma forma alternativa de substituição desse material seria o uso do suco de limão, contudo não proporciona agilidade no processo de pintura, por isso é pouco aplicado.

A implantação recente de painéis fotovoltaicos abastece de energia limpa o setor de corte de couro (Figura 05).

O solado é feito de borracha reciclada de pó de pneu fabricado no estado de Pernambuco, mas a cola que é usada para unir o forro ao solado é à base de petróleo. Depois das peças fabricadas separadamente, a sandália vai para a fôrma para ser finalizada. Essas fôrmas são reutilizáveis (Figura 06).

A linha usada no acabamento pode ser de material biodegradável.

O pó da serragem gerado no acabamento final é livre de cromo, não contaminando o meio ambiente, todavia não há o seu reaproveitamento (Figura 07).

A partir da análise da etapa de extração da matéria-prima, chegou-se ao Quadro 2. 


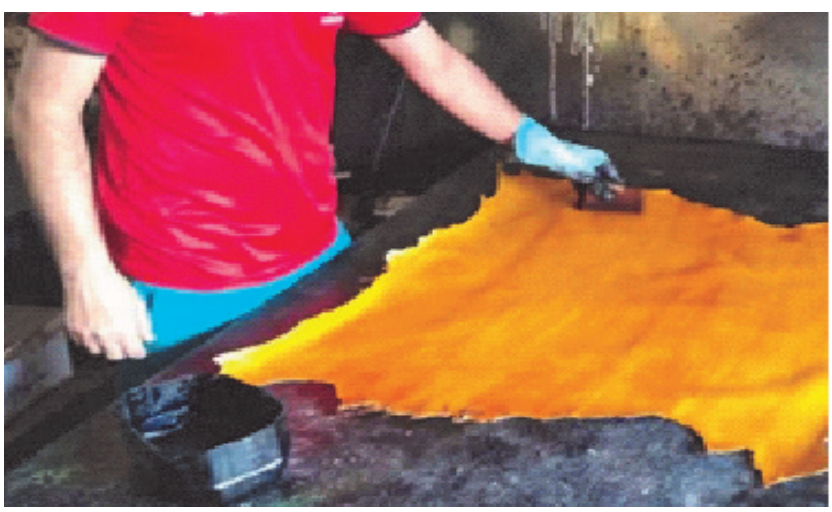

Figura 04 - Tingimento do couro Fonte: Autores (2019)

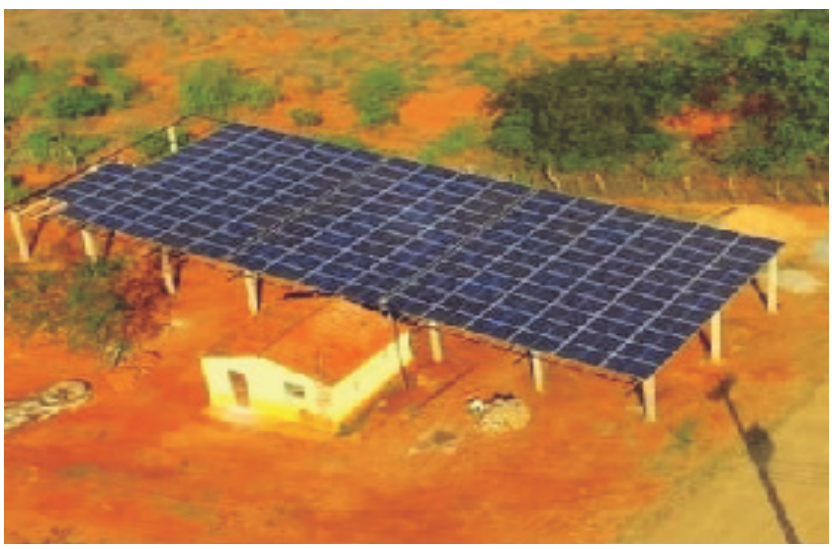

Figura 05 - Implantação de painéis solares Fonte: Autores (2019)

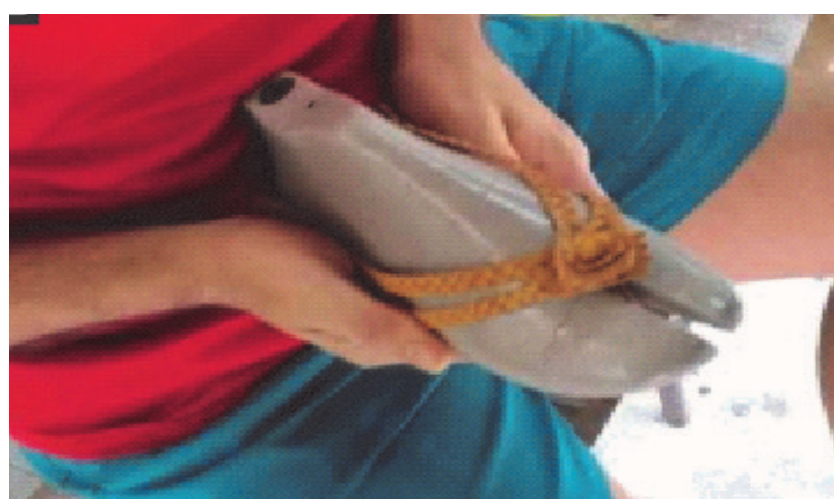

Figura 06 - Forma reutilizável Fonte: Autores (2019)

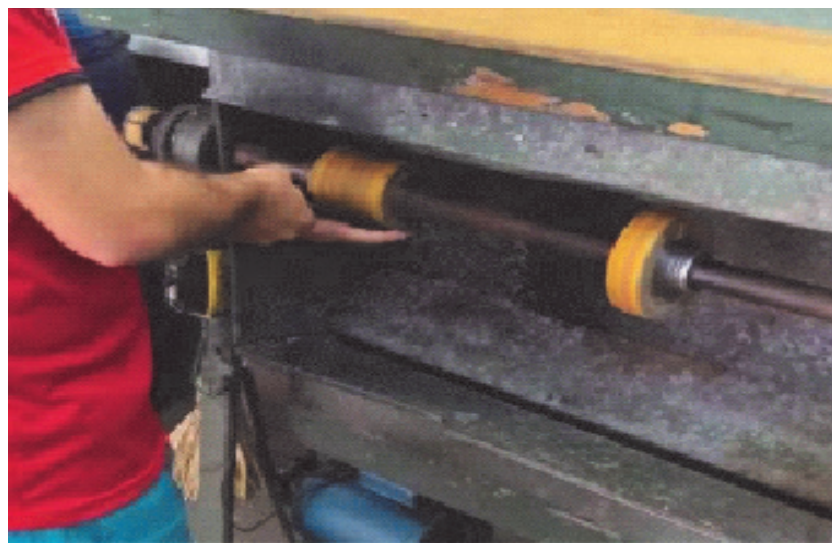

Figura 07 - Processo de acabamento Fonte: Autores (2019)

\begin{tabular}{|l|l|l|l|}
\hline ATIVIDADE & PRÁTICAS NÃO SUSTENTÁVEIS & PRÁTICAS SUSTENTÁVEIS & SUGESTÕES \\
\hline Pintura do couro & Utilização de tinta à base de petróleo & Utilizar suco de limão & $\begin{array}{l}\text { Melhorar o processo de } \\
\text { uso do suco de limão }\end{array}$ \\
\hline $\begin{array}{l}\text { Corte do couro para ob- } \\
\text { tenção das peças }\end{array}$ & $\begin{array}{l}\text { Não é realizado um planejamen- } \\
\text { to de melhor aproveitamento } \\
\text { do couro durante o corte. }\end{array}$ & $\begin{array}{l}1-\text { Utilização dos resíduos na } \\
\text { confecção de produtos ou } \\
\text { partes menores dos mesmos } \\
\text { - Implantação de pai- } \\
\text { néis fotovoltaicos }\end{array}$ & $\begin{array}{l}\text { Plano de corte buscando mini- } \\
\text { mizar a geração de resíduo }\end{array}$ \\
\hline--- & $\begin{array}{l}\text { Solado feito a partir de bor- } \\
\text { racha reciclada de pneu. }\end{array}$ & Utilizar cola a base de água \\
\hline Fôrma & A cola utilizada possui com- & A fôrma é reutilizável & Continuar utilizando a fôrma \\
\hline Linha de costura & ---- tóxicos & --- & Utilizar linhas biodegradáveis. \\
\hline Pó da lixadeira & Utilização de linhas comuns & O pó é livre de cromo & $\begin{array}{l}\text { Desenvolver estudos uso do pó } \\
\text { na fabricação de embalagens }\end{array}$ \\
\hline
\end{tabular}

Quadro 2 - Etapa 02 - Extração da Matéria-prima Fonte: Autores (2019)

\subsection{Etapa 03 - Distribuição para o mercado revendedor}

Geralmente as sandálias são comercializadas em atacado para fornecedores que revendem essas peças, em sua maioria em comércios regionais e feiras de artesanato.
Algumas peças são destinadas para o varejo, devido à grande procura por turistas.

As sandálias rasteiras são distribuídas em sacolas plásticas transparentes com fecho plástico e no varejo ainda são colocadas dentro de sacolas do tipo "boca de 
palhaço". Não apresentando nenhuma alternativa de embalagem sustentável. As sandálias embaladas são organizadas em sacos de nylon e armazenadas em caminhões ou carros com carroceria para serem transportadas até o destino final. Sem contar com nenhum meio de transporte alternativo e sustentável.

A partir da análise da etapa distribuição para o mercado revendedor, chegou-se ao Quadro 3.

\begin{tabular}{|l|l|l|l|}
\hline ATIVIDADE & PRÁTICAS NÃO SUSTENTÁVEIS & PRÁTICAS SUSTENTÁVEIS & SUGESTÕES \\
\hline $\begin{array}{l}\text { Comercialização em } \\
\text { forma de atacado }\end{array}$ & $\begin{array}{l}\text { Embalagem primária con- } \\
\text { feccionada em polímero }\end{array}$ & --- & $\begin{array}{l}\text { Utilização de embalagens susten- } \\
\text { táveis projetadas para o produto }\end{array}$ \\
\hline $\begin{array}{l}\text { Comercialização em } \\
\text { forma de varejo }\end{array}$ & $\begin{array}{l}\text { Embalagem primária e secundária } \\
\text { confeccionadas em polímero }\end{array}$ & --- & $\begin{array}{l}\text { Utilização de embalagens susten- } \\
\text { táveis projetadas para o produto }\end{array}$ \\
\hline Transporte & $\begin{array}{l}\text { Uso de caminhões ou carros com } \\
\text { carrocerias para longas distâncias para } \\
\text { otransporte de pequenas cargas }\end{array}$ & $\begin{array}{l}\text { Troca de mercadoria com } \\
\text { fornecedores da redondeza }\end{array}$ & $\begin{array}{l}\text { Planejamento da quantidade } \\
\text { de produto para transporte }\end{array}$ \\
\hline
\end{tabular}

Quadro 3 - Etapa 03 - Distribuição para o mercado revendedor

Fonte: Autores (2019)

\subsection{Etapa 04 - Uso}

Após a etapa de distribuição, o uso não é monitorado pela empresa, uma vez que se torna um objeto de uso pessoal. Não há um sistema de reparos de danos, sendo este realizado por terceiros.
Tampouco há uma conscientização da melhor forma de descarte da sandália a fim de reaproveitá-la ou reciclá-la.

A partir da análise da etapa de uso do produto, obteve-se o Quadro 4.

\begin{tabular}{|l|l|l|l|}
\hline ATIVIDADE & PRÁTICAS NÃO SUSTENTÁVEIS & PRÁTICAS SUSTENTÁVEIS & SUGESTÕES \\
\hline Utilização por parte do usuário & --- & --- & $\begin{array}{l}\text { Proporcionar maior dura- } \\
\text { bilidade ao produto }\end{array}$ \\
\hline Reparos & $\begin{array}{l}\text { Utilização de colas com elemen- } \\
\text { tos tóxicos e outros produtos }\end{array}$ & --- & $\begin{array}{l}\text { Local de reparo providenciado } \\
\text { pela própria cooperativa }\end{array}$ \\
\hline
\end{tabular}

Quadro 4 - Etapa 04 - Uso

Fonte: Autores (2019)

\subsection{Etapa 05 - Descarte}

O produto é descartado inadequadamente indo para aterros sem a possibilidade de reuso. (Quadro 5)

\begin{tabular}{|l|l|l|l|}
\hline ATIVIDADE & PRÁTICAS NÃO SUSTENTÁVEIS & PRÁTICAS SUSTENTÁVEIS & SUGESTÕES \\
\hline Descarte & Descarte direto em aterros sanitários & --- & $\begin{array}{l}\text { Postos de coleta e de be- } \\
\text { neficiamento para reapro- } \\
\text { veitamento do material }\end{array}$ \\
\hline
\end{tabular}

Quadro 5 - Etapa 05 - Descarte

Fonte: Autores (2019)

\section{CONCLUSÃO}

Nessa pesquisa, partimos do pressuposto de que é importante ter uma visão sistêmica de todo o processo que envolve um produto. Esse olhar holístico é fundamental para fechar ciclos, construindo na elaboração de uma cadeia produtiva sustentável.
Com relação à extração da matéria-prima verificam-se três situações problemáticas, a forma de abate do animal para a obtenção do couro (sem nenhum manejo humanizado), o curtimento e o tratamento dos resíduos sólidos. Destes, apenas vem sendo executada como manejo sustentável, o uso da casca do angico para realização do 
tratamento da pele. Todavia, a presença de profissionais mais jovens na composição das empresas da cooperativa, abre a possibilidade de mudanças futuras mais efetivas, referente a inclusão de aspectos sustentáveis na produção de sandálias em couro caprino.

Na fabricação identificam-se inúmeras etapas que desconsideram a inserção de ações sustentáveis tais como: a substituição da tinta a base de petróleo por uso do suco de limão; o aproveitamento do couro a partir do plano de corte visando minimização dos resíduos; substituição de cola com componentes tóxicos por cola a base de água; incorporação de linhas biodegradáveis na confecção da sandália; e estudo para reutilização do pó de lixamento como carga em compósitos.

Na etapa de distribuição para o mercado revendedor, o grande problema está nas embalagens utilizadas para o armazenamento e transporte do produto, nessa situação, são todas de material polimérico de difícil decomposição no meio ambiente. Como sugestão haveria a possibilidade do uso de biopolímeros. Outro problema está no uso de veículos de transporte inadequado para cargas pequenas.

Já na etapa que corresponde ao uso do produto não se verificou a presença de prática sustentável, como teste no produto para aferir sua durabilidade nem a possibilidade da própria cooperativa realizar os reparos nos produtos que foram danificados ou apresentaram defeitos durante o uso.

Por último, e não menos importante, está a questão do descarte do produto. Não foi identificada a preocupação da cooperativa com este item, seja através da comunicação com usuário, na forma de folder ou ícones nas embalagens, ou a propositura de local adequado para a entrega.

Um ponto bastante importante que precisa ser levantado em consideração é a formação dos profissionais que desenvolvem e fabricam os produtos. Como não são designers de formação acadêmica, verifica-se a falta de conhecimento referente a melhoria do design dos produtos visando a inclusão dos aspectos sustentáveis em toda a cadeia produtiva. Por mais que os designers estejam atualmente atrelados às questões ambientais durante a concepção dos artefatos, no caso dos artesãos, existe maior dificuldade na incorporação dessas premissas, em decorrência do método produtivo tradicional replicado por décadas de atividades. Todavia, a presença de profissionais mais jovens na composição das empresas da cooperativa, abra a possibilidade futura de mudanças mais efetivas visando inclusão de aspectos sustentáveis na produção de sandálias em couro caprino. Haja vista que, o consumidor está cada vez mais exigente em relação a origem, composição e fabricação dos produtos a serem adquiridos.
A partir de uma análise sistêmica do processo produtivo da sandália rasteiras de couro caprino na Cooperativa Arteza, foi possível identificar as práticas sustentáveis e não sustentáveis da produção, além de tornar possível a indicação de sugestões de práticas sustentáveis passíveis de serem inseridas no processo. Mostrando, dessa forma, que o processo não é totalmente sustentável, mas que apresenta diversas práticas que podem ser melhoradas ou substituídas, buscando torná-lo menos agressivo ao meio ambiente.

Verificou-se que é possível fechar ciclos de matéria e energia nesse processo produtivo e muitas das intervenções não demandariam um investimento financeiro elevado.

E como propõe Luigi Bistagnino com o design sistêmico, é importante ter uma visão para além dos fluxos materiais, observando também aspectos sociais e culturais envolvidos.

Nesta ótica conclui-se que a produção de sandálias de couro caprino contribui para a geração de renda, fortalecimento da economia e da identidade local e a permanência dos habitantes na região.

\section{REFERÊNCIAS}

ALVES, Ana Paula Ferreira; NASCIMENTO, Luis Felipe Machado do. PROATIVIDADE DE PRÁTICAS SUSTENTÁVEIS: UMA ANÁLISE DAS PRÁTICAS DA EMPRESA MERCUR S/A. REA UFSM : Revista de Administração da UFSM, Santa Maria, RS, v. 9, n. 0, p.25-42, ago. 2016.

BISTAGNINO, LUIGI. Design Sistêmico: uma abordagem interdisciplinar para a inovação. In: Moraes, Dijon; Krucken, Lia. Caderno de Estudos Avançados em Design: Sustentabilidade II. Barbacena, MG: EdUEMG, p. 13-30, 2009.

BRASIL, Centro das Indústrias de Curtumes do. $\mathbf{O}$ couro e o curtume brasileiro. Disponívelem: <http:// www.cicb.org .br/cicb/sobre-couro>. Acesso em: 02 ago. 2019.

CASTANHA, Ana Amélia Albuquerque Oliveira; AFONSO, ALCILIA A. A indústria do couro na Roliúde Nordestina In: XIX JORNADAS INTERNACIONALES DE PATRIMONIO INDUSTRIAL - INCUNA 2017, 2017, Gijon, Espanha.

CATALISA. O Tripé da Sustentabilidade na Prática:

Práticas Sustentáveis. Disponível em: <https://catalisa.org.br/catalisando/nossa-atuacao/>. Acesso em: 17 set. 2019.

CLEMENTINO, Thamyres Oliveira. Avaliação da Percepção dos Consumidores sobre a Comunicação de Sustentabilidade em Embalagens Alimenícias. 2017, 184 f. Dissertação (Mestrado em Design) 
- Universidade Federal de Campina Grande, Campina Grande-PB, 2017.

COBRASIL. A história do Couro. Disponível em: <https://www.cobrasil.com.br/pt/a-historia-do-couro >. Acesso em: 02 ago. 2019.

HART, Stuart. Capitalismo na Encruzilhada. Porto Alegre: Bookman, 2006, 232 p. ISBN 85-363-0672-6.

KAZAZIAN, Thierry. Haverá a idade das coisas leves: design e desenvolvimento sustentável. 2 ed. São Paulo: Editora SENAC São Paulo, 2009. 193 p. ISBN 978-85-7359-803-2

LAMB, Celina Maria Schmitt Rosa; NASS, Nilce Teresinha Puga. Desenvolvimento sustentável e avaliação do ciclo de vida. Brasília: Ibcti, p.33, 2014.

MANZINI, Ezio. Design para Inovação Social e Sustentabilidade: comunidades criativas, organizações colaborativas e novas redes projetuais. Rio de Janeiro: E-papers, 2008. 104 p. ISBN 979-85-7650-170-1.

MENEZES, Uilian Marques; GOMES, Almiralva Ferraz; DANTAS, Maria Zilda. Sustentabilidade e seus Benefícios: Práticas e Ações Sustentáveis Desenvolvidas em Empresas do Distrito Industrial dos Imborés. XVIII Semana do Administrador do Sudeste da Bahia: 35 Anos de Administração no Sertão da Ressaca: histórias, contribuições e perspectivas., Vitória da Conquista - Ba, v. 3, n. 1, p.1-15, out. 2016.

MONTE, Rammom. O Poder do Couro: Cooperativa reafirma sentimento de pertencimento do Caririzeiro e traz filhos de volta ao lar. 2018. Edição e captação de imagem: Vinícius Miron. Disponível em: $<$ http://portalcorreio.com.br/especial/poder-do-couro/>. Acesso em: 16 fev. 2018.

PAZ, Fábio Josende; LAUS, Giovandro Loreto; FARIAS, Jossimar Duarte. DIAGNÓSTICO DE PRÁTICAS SUSTENTÁVEIS: UMA ANÁLISE DA MATURIDADE SUSTENTÁVEL DAS MICRO E PEQUENAS EMPRESAS DE DOM PEDRITO. Reunir Revista de Administração Contabilidade e Sustentabilidade, [s.I.], v. 7, n. 3, p.1-17, 22 dez. 2017. Reunir Revista de Administracao, Contabilidade e Sustentabilidade. http://dx.doi. org/10.18696/reunir.v7i3.541.

PÊGO, Kátia; OLIVEIRA, Paulo. Design Sistêmico: relações entre território, cultura e ambiente no âmbito da estrada real. Strategic Design Research Journal, 7(3): 101-109 September-December 2014, Unisinos. SANTOS, Lucas Almeida dos et al. ANÁLISE DAS PRÁTICAS SUSTENTÁVEIS NO RAMO VAREJISTA: UMA
PERCEPÇÃO DOS COLABORADORES COM ÊNFASE NA EDUCAÇÃO AMBIENTAL. Reunir: Revista de Administração, Contabilidade e Sustentabilidade, [s.I.], v. 6, n. 1, p.37-55, 29 abr. 2016. Reunir Revista de Administracao, Contabilidade e Sustentabilidade. http://dx.doi.org/10.18696/reunir.v6i1.349.

SHENINI, Pedro Carlos; SCHIMITT, Valentina; SILVA, Fernando Amorin. Marketing Verde como abordagem estratégica frente ao novo perfil de consumo. Cpmark: Caderno Profissional de Marketing, Piracicaba, V.2, n.1, p.12-24, nov. 2014.

SPILLERE, Catarini et al. PRÁTICAS SUSTENTÁVEIS NAS ETAPAS DE PRODUÇÃO DE UMA INDÚSTRIA METAL MECÂNICA DO SUL DE SANTA CATARINA. Tecnologia e Ambiente, v. 22, p.34-51, dez. 2016. Fundação Educacional de Criciuma- FUCRI. http://dx.doi. org/10.18616/ta.v21i0.2961

www.artezacooperativa.com.br 


\section{AUTORES}

ORCID: https://orcid.org/0000-0001-8488-2781

ANA AMÉLIA ALBUQUERQUE DE OLIVEIRA CASTANHA | UFCG PPGDesign | Correspondência para: Rua Gilvan Barbosa 50 - Itararé, Campina Grande, CEP: 58411-046Residencial Maria Lúcia, Apt 302 | e-mail: ana_2aoli@hotmail.com

ORCID: https://orcid.org/0000-0002-7173-2415

GEISLAYNE MENDONÇA SILVA | UFCG - PPGDesign | Correspondência para: Avenida Lírio do Amazonas, 668 - Lago Azul Manaus, Amazonas, CEP: 69019600 | email: geislayne94@gmail.com

ORCID: https://orcid.org/0000-0002-8532-1860

JULIATELESDASILVA,Dr.|UFCG-PPGDesign|Correspondência para: Rua Aprígio Veloso, 882 - Bloco BO Campina Grande, Paraíba, CEP: 58429-900 | e-mail: julitateles@gmail.com

ORCID: https://orcid.org/0000-0002-0874-9345

ITAMAR FERREIRA DA SILVA, Dr. | Coordenador do PPGDesign UFCG | Professor na Unidade Acadêmica de Design - UFCG | Correspondência para: Universidade Federal de Campina Grande, Unidade acadêmica de Design, 58429900 Campina Grande, PB - Brasil | e-mail: itamarfs0210@gmail. com | Lattes: http:// lattes.cnpq.br/7437181641061519

\section{COMO CITAR ESTE ARTIGO}

CASTANHA, Ana Amelia Alburquerque de Oliveira; SILVA, Geislayne Mendonça; SILVA, Julia Teles da; SILVA, Itamar Ferreira da. Práticas Sustentáveis e Não Sustentáveis na Produção de Sandálias de Couro Caprino em Cabaceiras-PB. MIX Sustentável, [S.I.], v. 6, n. 4, p. 51-60, ago. 2020. ISSN 24473073. Disponível em:<http://www.nexos.ufsc.br/index.php/ mixsustentavel>. Acesso em: dia mês. ano. doi:https:// doi.org/10.29183/2447-3073.MIX2020.v6.n4.51-60.

DATA DE ENVI0: 27/01/2020

DATA DE ACEITE: 05/06/2020 